Research Article

\title{
Characterizing distal peripheral neuropathy in type 2 diabetes mellitus in a semi-urban community setting in Peru
}

\author{
Meera F lyengar ${ }^{1}$, Antonio Bernabe-Ortiz ${ }^{2}$ \\ 1 University of Texas Southwestern Medical Center, Dallas, Texas, USA, ${ }^{2}$ CRONICAS Centre of Excellence in Chronic Diseases, Universidad Peruana \\ Cayetano Heredia, Lima, Peru \\ Keywords: global health \\ https://doi.org/10.29392/joghr.3.e2019077
}

\section{Journal of Global Health Reports}

Vol. 3, 2019

\begin{abstract}
Background
Distal peripheral neuropathy (DPN) is a devastating complication of type 2 diabetes that is causing medical and economic burden worldwide, especially in developing nations like Peru. Hospital prevalence of DPN has been determined in Peru, but information characterizing DPN in the community is scarce. This study characterized DPN among individuals with Type 2 diabetes using a population-based survey in Peru.
\end{abstract}

\section{Methods}

Cross-sectional, population-based study conducted in Tumbes, Peru. Participants were categorized by glycemic status measured by an oral glucose tolerance test. Neuropathic status was measured by biothesiometry.

\section{Result}

A total of 1,607 participants were included, mean age 48.2 (standard deviation (SD)=0.3), and 810 (50.3\%) women. A total of $176(11.0 \%$, 95\% confidence interval $(\mathrm{CI})=9.5-12.6 \%)$ persons had type 2 diabetes and 272 (17\%; 95\% CI=15.1-18.8\%) had dysglycemia. Among those with type 2 diabetes, 105 (59.7\%) were aware of their diagnosis, with 94 (89.5\%) on treatment, and only 30 (28.6\%) with appropriate control. DPN prevalence was $44.3 \%$ among those with type 2 diabetes and 19.8\% among those with dysglycemia. In multivariable model, type 2 diabetes, but not dysglycemia, was associated with a 1.28 -increased $(95 \% \mathrm{CI}=1.13-1.45)$ prevalence of DPN compared to normal controls.

\section{Conclusions}

There is a high prevalence of DPN at community level. The high prevalence of DPN and high amount of undiagnosed and uncontrolled cases of type 2 diabetes demonstrate a need for earlier detection, stricter glycemic control, and improved screening, especially in resource-constrained settings like Peru.

Type 2 diabetes is no longer a problem isolated to highincome countries. The prevalence of type 2 diabetes has almost doubled over the past decades, from $4.7 \%$ to $8.5 \%$, with the fastest rise in low-and-middle income countries (LMICs). ${ }^{1,2}$

Neuropathy is a serious complication of type 2 diabetes, particularly in LMICs, and distal peripheral neuropathy (DPN) is the most common type. Standard methods of diagnosing DPN include nerve conduction studies and skin biopsies; however, clinical symptom scales and monofilament testing are more commonly used in primary care settings. ${ }^{3,4}$ The use of vibration perception threshold (VPT) testing has also been validated as a method of diagnosing DPN. ${ }^{5}$ Studies from LMICs have showed hospital and community prevalence rates ranging between $20 \%$ and $60 \% .6,7$ A cross-sectional study conducted in Peru demonstrated a hospital prevalence of $57 \%{ }^{8}$
DPN is often poorly managed in LMICs due to lack of resources. Approximately $25 \%$ of patients with DPN will develop foot ulcers, many of which then proceed to amputations, which forebode a high mortality rate. ${ }^{9,10}$ In addition to the medical burden, DPN among cases of type 2 diabetes poses a significant financial burden on patients and their families. A cost-analysis study in Peru reported costs of US\$ 74.5 million for high-risk individuals with diabetes in a single year. ${ }^{11}$

Given such a high hospital prevalence rate of DPN among cases of type 2 diabetes in Peru, there is a need to determine the rate of this complication at the population level. Therefore, this study aimed to determine the prevalence of DPN in a community-based setting in Peru. Association of DPN with abnormal glycemic status was also assessed. 


\section{METHODS}

\section{SETTING AND STUDY POPULATION}

This was a population-based, cross-sectional study conducted in Tumbes, a semi-urban area in the north of Peru. Details about participant selection and procedures have previously been reported. ${ }^{12}$ Briefly, based on the most recent census data in the area, participants were selected using a sex-stratified random sampling method.

Inclusion criteria were age between 30 and 69 years, full time residency in the study area ( $\geqslant 6$ months), and ability to provide informed consent. Those bedridden, or with physical disabilities preventing anthropometric measurements, as well as pregnant women, were excluded. One participant from each household was selected to avoid clustering.

\section{OUTCOME VARIABLE}

The outcome of interest was DPN assessed by VPT testing. VPT was measured with a biothesiometer (Diabetik Foot Care India Pvt Ltd, Chennai, India). Participants were asked to lie in the supine position, and the stylus of the biothesiometer was applied perpendicular to the pulp on the plantar surface of the hallux of both feet. The amplitude of the vibration was gradually increased until the participant could detect the vibration. This process was performed in triplicate for each foot. The participant was considered to have DPN if the average of the three measurements in either foot was $\geqslant 25 \mathrm{mV} .^{13}$ In addition, abnormal VPT was also included and defined as VPT $\geqslant 10 \mathrm{mV}$ but $<25 \mathrm{mV}$. 14

\section{EXPOSURE VARIABLE}

The exposure of interest was glycemic status (normal, dysglycemia, and type 2 diabetes). Type 2 diabetes was defined by the oral glucose tolerance test criteria as per the World Health Organization threshold (fasting glucose $\geqslant 126 \mathrm{mg} / \mathrm{dL}$ $(\geqslant 7.0 \mathrm{mmol} / \mathrm{L})$ or 2 -hour plasma glucose $\geqslant 200 \mathrm{mg} / \mathrm{dL}(\geqslant 11.1$ $\mathrm{mmol} / \mathrm{L})$ ). Self-reported type 2 diabetes diagnosis by a physician and current treatment for type 2 diabetes were also used in the definition. Dysglycemia was defined as either the presence of impaired glucose tolerance or impaired fasting glucose, both of which were defined according to criteria recommended by the World Health Organization.

Individuals who were previously unaware of their glucose status and had a fasting glucose $\geqslant 126 \mathrm{mg} / \mathrm{dL}(\geqslant 7.0 \mathrm{mmol} / \mathrm{L})$ or 2 -hour plasma glucose $\geqslant 200 \mathrm{mg} / \mathrm{dL}(\geqslant 11.1 \mathrm{mmol} / \mathrm{L})$ were considered as having undiagnosed type 2 diabetes. On the other hand, those with type 2 diabetes and aware of their condition were categorized as controlled cases if the result of glycated hemoglobin (HbA1c) was $<48 \mathrm{mmol} / \mathrm{mol}$ $(<6.5 \%)$

\section{OTHER VARIABLES}

Some variables were also assessed for population description as well as potential confounders in the association of interest. Among socio-demographic variables were age, sex, education level, socioeconomic status, and health insurance. Among behavioral variables were daily smoking, selfreported and based on the consumption of at least one cig- arette per day, and alcohol consumption, assessed by the Alcohol Use Disorder Identification Test (AUDIT), with a score of $\geqslant 4$ considered positive for men, $\geqslant 3$ for women. ${ }^{15}$ Anthropometric measures collected were body mass index, waist circumference, and blood pressure (See Table 1 for further details).

\section{PROCEDURES}

Fieldworkers went from house to house to recruit participants. Written informed consent was obtained before undergoing study procedures. Socio-demographic information, medical and familial history, and behavioral variables were collected and recorded by trained staff on tablets in an application built using Open Data Kit (ODK, University of Washington Department of Computer Science and Engineering, Seattle, WA, USA).

Then, anthropometric measurements (ie, weight, height, waist circumference) and blood pressure were obtained. VPT testing was then conducted using a biothesiometer as detailed earlier. Trained laboratory staff collected a fasting glucose blood sample after consent was obtained and another blood sample two hours after a $75 \mathrm{~g}$ glucose load was administered. A Cobas Modular Platform and Roche Diagnostic reagents were used to analyze glucose levels. HbA1c was assessed using high-performance liquid chromatography (D10-BIORAD, Germany), which is traceable to the National Glycohemoglobin Standarization Program.

\section{STATISTICAL ANALYSIS}

Analysis was performed using STATA 15.0 for Macintosh (Stata Corp, College Station, TX, US). Study population characteristics were tabulated by means and standard deviations (SD) for continuous variables and percentages for categorical variables. Chi-squared tests were used to compare categorical variables, and $p$-values $<0.05$ were considered significant.

To determine the strength of the association between variables of interest, Poisson regression models with robust variance were used. ${ }^{16}$ Crude and adjusted models were generated, the latter controlling for sex, age, education level, socioeconomic status, daily smoking, alcohol use disorder, waist circumference, and high blood pressure levels.

\section{ETHICS}

The protocol, consent, and questionnaires received approval from the Institutional Review Board at the Universidad Peruana Cayetano Heredia in Lima, Peru and the London School of Hygiene and Tropical Medicine, London, UK.

\section{RESULTS}

\section{POPULATION CHARACTERISTICS}

A total of 1,609 participants were enrolled in the study. However, only 1,607 were analyzed, as 2 did not have OGTT results. The mean age of participants was 48.2 (standard deviation $(\mathrm{SD})=10.6) ; 809$ (50.3\%) were women, and 341 (21.2\%) had $12+$ years of education. 
Table 1. Characteristics of the study population by glucose status $(n=1,607)$

\begin{tabular}{|c|c|c|c|c|}
\hline \multirow[t]{2}{*}{ Characteristic } & \multicolumn{4}{|c|}{ Glucose Status } \\
\hline & Normal & Dysglycemia & Diabetes & $P$-value \\
\hline Sex & $(n=1,159)$ & $(n=272)$ & $\mathrm{n}=176)$ & \\
\hline Men & $612(52.8 \%)$ & $112(41.2 \%)$ & $74(42.1 \%)$ & $<0.001$ \\
\hline \multicolumn{5}{|l|}{ Age: } \\
\hline$<40$ & 372 (32.1\%) & $54(19.9 \%)$ & $14(7.9 \%)$ & \multirow{4}{*}{$<0.001$} \\
\hline $40-49$ & $354(30.5 \%)$ & $81(29.8 \%)$ & $45(25.6 \%)$ & \\
\hline $50-59$ & 264 (22.8\%) & 76 (27.9\%) & 69 (39.2\%) & \\
\hline$\geq 60$ & $169(14.6 \%)$ & 61 (22.4\%) & 48 (27.3\%) & \\
\hline \multicolumn{5}{|l|}{ Education level: } \\
\hline Primary & 336 (29.0\%) & 102 (37.5\%) & 80 (45.4\%) & \multirow{3}{*}{$<0.001$} \\
\hline Secondary & $559(48.2 \%)$ & $116(42.7 \%)$ & $73(41.5 \%)$ & \\
\hline Superior & $264(22.8 \%)$ & $54(19.8 \%)$ & $23(13.1 \%)$ & \\
\hline \multicolumn{5}{|l|}{ SES based on assets: } \\
\hline Low & 370 (31.9\%) & $100(36.8 \%)$ & $68(38.6 \%)$ & \multirow{3}{*}{0.29} \\
\hline Middle & 408 (35.2\%) & $89(32.7 \%)$ & $53(30.1 \%)$ & \\
\hline High & 381 (32.9\%) & $83(30.5 \%)$ & 55 (31.3\%) & \\
\hline \multicolumn{5}{|l|}{ Health insurance: } \\
\hline No & $109(9.4 \%)$ & $20(7.4 \%)$ & $11(6.3 \%)$ & 0.26 \\
\hline \multicolumn{5}{|l|}{ Daily smoking: } \\
\hline Yes & $72(6.2 \%)$ & $12(4.4 \%)$ & $8(4.6 \%)$ & 0.40 \\
\hline \multicolumn{5}{|l|}{ Alcohol use disorder: } \\
\hline AUDIT (+) & $106(9.2 \%)$ & $7(2.6 \%)$ & $8(4.6 \%)$ & $<0.001$ \\
\hline \multicolumn{5}{|l|}{ BMI: } \\
\hline$<25 \mathrm{~kg} / \mathrm{m}^{2}$ & $341(29.4 \%)$ & $47(17.3 \%)$ & $37(21.0 \%)$ & \multirow{3}{*}{$<0.001$} \\
\hline $25-29.99 \mathrm{~kg} / \mathrm{m}^{2}$ & $514(44.4 \%)$ & $111(40.8 \%)$ & $81(46.0 \%)$ & \\
\hline$\geq 30 \mathrm{~kg} / \mathrm{m}^{2}$ & $304(26.2 \%)$ & $114(41.9 \%)$ & $58(33.0 \%)$ & \\
\hline \multicolumn{5}{|l|}{ Waist circumference: } \\
\hline$<90 \mathrm{~cm}$ & 450 (38.8\%) & 76 (27.9\%) & 44 (25.0\%) & \multirow{3}{*}{$<0.001$} \\
\hline $90-99 \mathrm{~cm}$ & $460(39.7 \%)$ & $98(36.0 \%)$ & $68(38.6 \%)$ & \\
\hline $100+c m$ & $249(21.5 \%)$ & $98(36.1 \%)$ & $64(36.4 \%)$ & \\
\hline \multicolumn{5}{|l|}{ Hypertension: } \\
\hline Yes & 252 (21.7\%) & 93 (34.2\%) & 72 (40.9\%) & $<0.001$ \\
\hline
\end{tabular}

SES - Socioeconomic status, AUDIT - Alcohol use disorder identification test, BMI - Body mass index

Out of the 1607 individuals, 176 (11.0\%; 95\% confidence interval $(\mathrm{CI})=9.5-12.6)$ had type 2 diabetes and $272(16.9 \%$; 95\% CI=15.1-18.9) presented dysglycemia. A greater proportion of individuals with type 2 diabetes and dysglycemia were women compared to those with normal glucose status $(P<0.001)$. Those with type 2 diabetes were older $(P<0.001)$, had a lower level of education $(P<0.001)$, higher waist circumference $(P<0.001)$, and higher prevalence of high BP $(P<0.001)$ compared to those with dysglycemia and normal glucose status (See details in Table 1).

Finally, among those with type 2 diabetes, 105 (59.7\%) were aware of their diagnosis before the study. Among these participants, 94 (89.5\%) reported being on treatment, while 30 (28.6\%) had their type 2 diabetes appropriately controlled.

\section{PREVALENCE OF DPN AND GLUCOSE STATUS}

A total of 309/1607 participants (19.2\%, 95\% CI=17.3-21.2) had results compatible with DPN, and 933 (58.1\%; 95\% $\mathrm{CI}=55.6-60.5)$ had abnormal biothesiometer results. Mean age was higher in the DPN group (57.2 years, $S D=8.0$ ) compared to the abnormal biothesiometer result and normal group (47.9 years, $\mathrm{SD}=10.0$ and 41.2 years, $\mathrm{SD}$ : 8.1 , respectively; $P<0.001)$. A greater proportion of individuals with DPN were men (59.8\%) compared to those with abnormal and normal results $(P<0.001)$. Details of sociodemographic variables assessed according to biothesiometer result are shown in Table 2.

Prevalence of DPN was $44.3 \%$ among individuals with type 2 diabetes, $19.8 \%$ among those with dysglycemia, and $15.3 \%$ among those with normal glucose status (Table 2). In our multivariable model, after controlling for sex, age, ed- 
Table 2. Characteristics of the study population by biothesiometer results

\begin{tabular}{|c|c|c|c|c|}
\hline \multirow{2}{*}{ Characteristics } & \multicolumn{4}{|c|}{ Biothesiometer result } \\
\hline & Normal $(<10 \mathrm{mV})$ & Abnormal (10-25 mV) & Neuropathy (>25 mV) & $P$-value \\
\hline Sex & $(n=365)$ & $(n=935)$ & $(n=309)$ & \multirow{3}{*}{$<0.001$} \\
\hline Men & $148(18.5 \%)$ & $476(59.6 \%)$ & $175(21.9 \%)$ & \\
\hline Women & $217(26.8 \%)$ & $459(56.7 \%)$ & $134(16.5 \%)$ & \\
\hline \multicolumn{5}{|l|}{ Age: } \\
\hline$<40$ & 191 (43.3\%) & $242(54.9 \%)$ & $8(1.8 \%)$ & \multirow{4}{*}{$<0.001$} \\
\hline $40-49$ & $115(24.0 \%)$ & $314(65.4 \%)$ & $51(10.6 \%)$ & \\
\hline $50-59$ & $51(12.5 \%)$ & $236(57.7 \%)$ & $122(29.8 \%)$ & \\
\hline$>60$ & $8(2.9 \%)$ & $143(51.2 \%)$ & $128(45.9 \%)$ & \\
\hline \multicolumn{5}{|l|}{ Education level: } \\
\hline$<7$ years & $53(10.2 \%)$ & $294(56.7 \%)$ & $172(33.1 \%)$ & \multirow{3}{*}{$<0.001$} \\
\hline $7-11$ years & $188(25.1 \%)$ & $443(59.2 \%)$ & $118(15.7 \%)$ & \\
\hline $12+$ years & $124(36.4 \%)$ & $198(58.1 \%)$ & $19(5.6 \%)$ & \\
\hline \multicolumn{5}{|c|}{ Socioeconomic status: } \\
\hline Low & $94(17.4 \%)$ & $323(59.8 \%)$ & $123(22.8 \%)$ & \multirow{3}{*}{$<0.001$} \\
\hline Middle & $124(22.6 \%)$ & 319 (58.0\%) & 107 (19.4\%) & \\
\hline High & $147(28.3 \%)$ & $293(56.5 \%)$ & $79(15.2 \%)$ & \\
\hline \multicolumn{5}{|l|}{ Health insurance: } \\
\hline No & $37(26.4 \%)$ & $76(54.3 \%)$ & $27(19.3 \%)$ & \multirow{2}{*}{0.51} \\
\hline Yes & $328(22.3 \%)$ & $859(58.5 \%)$ & $282(19.2 \%)$ & \\
\hline \multicolumn{5}{|l|}{ Daily smoking: } \\
\hline No & $351(23.1 \%)$ & $884(58.3 \%)$ & $282(18.6 \%)$ & \multirow{2}{*}{0.02} \\
\hline Yes & $14(15.2 \%)$ & $51(55.4 \%)$ & $27(29.4 \%)$ & \\
\hline \multicolumn{5}{|c|}{ Alcohol use disorder: } \\
\hline AUDIT (-) & $337(22.7 \%)$ & $863(58.0 \%)$ & $288(19.4 \%)$ & \multirow{2}{*}{0.87} \\
\hline AUDIT (+) & $28(23.1 \%)$ & $72(59.5 \%)$ & $21(17.4 \%)$ & \\
\hline \multicolumn{5}{|l|}{ BMI: } \\
\hline$<25 \mathrm{~kg} / \mathrm{m}^{2}$ & $88(20.7 \%)$ & $245(57.7 \%)$ & $92(21.6 \%)$ & \multirow{3}{*}{0.002} \\
\hline $25-29.99 \mathrm{~kg} / \mathrm{m}^{2}$ & $155(21.9 \%)$ & $443(62.6 \%)$ & $110(15.5 \%)$ & \\
\hline$>30 \mathrm{~kg} / \mathrm{m}^{2}$ & $122(25.6 \%)$ & $247(51.9 \%)$ & $107(22.5 \%)$ & \\
\hline \multicolumn{5}{|c|}{ Waist circumference: } \\
\hline$<90 \mathrm{~cm}$ & $155(27.2 \%)$ & $326(57.2 \%)$ & $89(15.6 \%)$ & \multirow{3}{*}{$<0.001$} \\
\hline $90-99 \mathrm{~cm}$ & $140(22.3 \%)$ & $386(61.5 \%)$ & $102(16.2 \%)$ & \\
\hline $100+\mathrm{cm}$ & $70(17.0 \%)$ & $223(54.3 \%)$ & $118(28.7 \%)$ & \\
\hline \multicolumn{5}{|l|}{ Hypertension: } \\
\hline No & 309 (25.9\%) & $694(58.2 \%)$ & 189 (15.9\%) & \multirow{2}{*}{$<0.001$} \\
\hline Yes & $56(13.4 \%)$ & $241(57.8 \%)$ & $120(28.8 \%)$ & \\
\hline \multicolumn{5}{|l|}{ Glucose status: } \\
\hline Normal & $283(24.4 \%)$ & $699(60.3 \%)$ & $177(15.3 \%)$ & \multirow{3}{*}{$<0.001$} \\
\hline Dysglycemia & $63(23.2 \%)$ & 155 (57.0\%) & $54(19.8 \%)$ & \\
\hline Diabetes & $19(10.8 \%)$ & 79 (44.9\%) & $78(44.3 \%)$ & \\
\hline
\end{tabular}

ucation level, socioeconomic status, daily smoking, alcohol use disorder, waist circumference, and hypertension status, type 2 diabetes, but not dysglycemia, was associated with an increased prevalence of DPN compared to the normal glucose status group ( $\mathrm{PR}=1.28,95 \% \mathrm{CI} 1.13-1.45$, Table 3).
AWARENESS OF TYPE 2 DIABETES STATUS, DURATION OF TYPE 2 DIABETES, AND DPN

Among patients with type 2 diabetes, a higher proportion of participants with a previous diagnosis had DPN compared to those who were unaware of their diagnosis $(57.1 \%$ vs. $24.7 \%, P<0.001)$. However, there was no difference in the prevalence of DPN when comparing individuals with type 2 
Table 3. Association between glucose status and diabetic peripheral neuropathy - crude and adjusted regression models

\begin{tabular}{lccc}
\hline Biothesiometer result & Crude Model & Model 1* & Model 2† \\
\hline Abnormal vs. normal $(n=1,298)$ & PR $(95 \% \mathrm{Cl})$ & PR (95\% Cl) & PR (95\% Cl) \\
Normal & 1 (Reference) & 1 (Reference) & 1 (Reference) \\
Dysglycemia & $1.00(0.91-1.10)$ & $0.95(0.86-1.03)$ & $0.94(0.86-1.03)$ \\
Diabetes & $1.13(1.02-1.26)$ & $1.05(0.95-1.16)$ & $1.03(0.93-1.15)$ \\
Neuropathy vs. normal $(\mathrm{n}=674)$ & $\mathrm{PR}(95 \% \mathrm{Cl})$ & $\mathrm{PR}(95 \% \mathrm{Cl})$ & $\mathrm{PR}(95 \% \mathrm{Cl})$ \\
Normal & 1 (Reference) & 1 (Reference) & $1($ Reference) \\
Dysglycemia & $1.20(0.96-1.51)$ & $1.04(0.88-1.24)$ & $1.01(0.84-1.20)$ \\
Diabetes & $2.09(1.80-2.43)$ & $1.31(1.17-1.48)$ & $1.28(1.13-1.45)$ \\
\hline
\end{tabular}

$\mathrm{PR}$ - prevalence ratio, CI - confidence interval

*Adjusted for sex, age, education level, and socioeconomic status

†Adjusted for sex, age, education level, socioeconomic status, smoking, alcohol, waist circumference, and hypertension

diabetes on treatment to those not on treatment $(59.1 \%$ vs. 41.7\%, $P=0.40$ ).

Duration of disease was available for the 105 participants aware of their diabetes diagnosis. The mean duration was $6.3(\mathrm{SD}=6.1$, range $=0-32$ ) years. DPN was present in $25 / 55$ (45.5\%) individuals with $<5$ years of disease, whereas it was present in $30 / 50(70.0 \%)$ individuals with $\geqslant 5$ years of disease $(P=0.03)$.

\section{DISCUSSION}

\section{MAIN FINDINGS}

A significant association between type 2 diabetes and DPN, even after accounting for potential confounders, is reported in this manuscript. We also found a lower prevalence of DPN in the community compared to the hospital prevalence found in previous studies in Peru (35.8\% vs. 56.6\%), which is expected given that participants from hospitals tend to be more ill and present with more severe forms of disease. Additionally, there were a large number of participants with signs compatible with non-diabetic neuropathy, and a large number of undetected cases of diabetes in the community.

\section{COMPARISON WITH PREVIOUS STUDIES}

Our DPN prevalence estimate, based on a community-based survey, matches the global prevalence of DPN reported in a meta-analysis conducted in 2016. ${ }^{17}$ This meta-analysis pooled various hospital and community-based studies together, including two separate studies conducted in Brazil and Mexico. DPN prevalence was found to be $26.5 \%$ in an outpatient setting in Brazil and $40.8 \%$ in a community setting in Mexico. ${ }^{18,19}$ Besides the studies mentioned above, there is very little additional data regarding prevalence of DPN in Latin American countries. It is important to recognize that, though a global prevalence value of DPN exists, rates vary throughout the globe, with $77 \%$ of people with DPN living in low-middle income countries. This distribution could be attributed to genetic predisposition, lifestyle behaviors, level of glycemic control, duration of asymptomatic hyperglycemia, and poor access to effective treatment. 17,20,21 Therefore, more studies like this are necessary in Latin America in order to understand the epidemiology and impact of DPN in this region. ${ }^{22}$

The variability in DPN prevalence as reported in the aforementioned systematic review could also be due to differences in diagnostic methods and cutoff criteria used. Tools used to diagnose DPN range from symptom scales such as the Neuropathy Disability Score, Neuropathy Symptom Score, Michigan Neuropathy Screening Instrument, ${ }^{23}$ to physical exam procedures like the Semmes-Weinstein Monofilament Examination and VPT testing, to more advanced techniques that are typically gold-standard for research studies: electromyography and nerve conductions studies. ${ }^{24}$ The accuracy of these tests varies, which can impact prevalence rates. In this study, we used VPT to determine neuropathic status. Although a valid method, the sensitivity and specificity are lower when compared to nerve conduction studies; therefore, we could possibly be underestimating the number of DPN cases. ${ }^{5,25}$ While it is important to consider the practicality of applying a diagnostic method to a target population, an alternative methodology that would improve our study would be to determine neuropathy with a gold-standard technique.

The high percentage of abnormal biothesiometer results (VPT $\geqslant 10 \mathrm{mV}$ but $<25 \mathrm{mV}$ ) found in participants from all three groups (normal, dysglycemia, type 2 diabetes) is important to note. We also found that a portion of normal controls and individuals with dysglycemia had results compatible with DPN. Both findings highlight the importance of considering other causes of nerve damage (ie, B12 deficiency, hypothyroidism) and confounding factors (ie, age, obesity).

Alternatively, the fact that some individuals with dysglycemia had results compatible with DPN could point to neuropathy as an early sign or risk factor for disease. A growing body of literature has linked prediabetes (ie, dysglycemia) and obesity with increased risk for DPN and nondiabetic neuropathy. ${ }^{26}$ However, damage is thought to involve mainly small nerve fibers, which would not explain the large nerve fiber damage detected by VPT that we found. Therefore, although dysglycemia is a risk for developing neuropathy because it progresses to type 2 diabetes, it cannot be the sole cause. ${ }^{27}$ This latter theory fits the results we found in our regression model, thus corroborating the fact 
that multiple factors (ie, abnormal glucose levels, obesity, age, and hypertension) contribute to the vessel damage that subsequently manifests as nerve damage seen in individuals with dysglycemia.

\section{OTHER RELEVANT RESULTS}

The results of this study emphasize the need for greater surveillance in screening for type 2 diabetes and its complications in the community. Additionally, it highlights the need for better implementation of current screening practices. Many participants were unaware they had type 2 diabetes prior to the study, a phenomenon that has been found in other population-based studies. ${ }^{28}$ However, this value was much higher in Peru compared to other countries; $17 \%$ of individuals with type 2 diabetes had findings compatible with neuropathy at the time of diagnosis. ${ }^{20,21}$ The high percentage of people with undiagnosed type 2 diabetes and DPN in Peru ultimately indicates a need for earlier detection. However, it also points to neuropathy as a potential bridge between diagnosed and undiagnosed cases in the community. The significantly higher number of people aware of diabetes who also had neuropathy compared to those unaware of type 2 diabetes suggests that neuropathy may be a prompter for people in the community to get screened for type 2 diabetes. Perhaps in resource-constrained settings, detection of neuropathy can be a gateway to type 2 diabetes diagnosis and getting proper treatment. Future studies are needed to investigate causes for delay in type 2 diabetes detection, and perhaps one way to approach this would be to characterize what symptoms people in resource-constrained settings initially present with. Learning how people initially present with type 2 diabetes could provide future direction on how to improve this delay in detection and care.

The large number of uncontrolled cases of type 2 diabetes demonstrates the difficulty of achieving glycemic control among individuals in the community. In large randomized controlled trials, strict glycemic control has been shown to prevent and improve neuropathy in type 1 diabetes mellitus, but has been less evident for type 2 diabetes. ${ }^{29}$ A hypothesized reason is that the presence of other risk factors (ie, hypertension, obesity, hyperlipidemia, chronic inflammation) in individuals with diabetes adds additional mechanisms that contribute to vascular damage leading to neuropathy symptoms. Nevertheless, glycemic control is still an important aspect of type 2 diabetes control, as poor glucose control contributes to increased complication rates, and complications from neuropathy (ie, foot ulcers and deformities) are exacerbated by poor glucose control. ${ }^{30}$ Therefore, glycemic control can be a major area healthcare workers can focus on in clinical practice to improve outcomes of type 2 diabetes in LMICs such as Peru.

Characterizing DPN in a community setting is important, as data will help guide future interventions and policy to improve health outcomes. Additionally, the results highlight the need for better implementation of clinical screening practices for DPN (ie, at-home foot exams, regular check-ups with annual foot exams using appropriate tools, comprehensive diabetic foot care programs) in resourceconstrained settings. Finally, these results contribute to the growing body of knowledge about DPN in South America, an area where data is relatively scarce.

\section{STRENGTHS AND LIMITATIONS}

This study was a community-based survey and thus included a large sample size and avoided biases associated with hospital-based studies. Limitations, however, are present. Possible selection bias can be present, as we only selected participants between ages 30-69 from a certain region in Peru.

VPT has been validated as a tool for diagnosing neuropathy; however, screening guidelines recommend using multiple modalities to characterize DPN. By using VPT alone, we are primarily assessing for large nerve fiber damage and may miss detecting early manifestations of DPN, which involve small nerve fibers. Thus, some cases of neuropathy could be missed. ${ }^{27}$ As mentioned earlier, VPT is less sensitive than the gold standard, which could underestimate prevalence further. Additionally, we did not inquire into other causes of neuropathy besides type 2 diabetes. Although OGTT is one of the gold standards for diagnosing diabetes, WHO and ADA guidelines recommend two assessments with any blood test to diagnose type 2 diabetes. By only using one OGTT assessment to classify individuals in this study, some misclassification may arise.

\section{CONCLUSIONS}

We detected a high prevalence of DPN in the community, although lower than hospital-based studies. The high prevalence of DPN along with the high amount of undiagnosed and uncontrolled cases of type 2 diabetes demonstrate a need for earlier detection, stricter glycemic control, and studies investigating barriers to care in order to improve outcomes of disease, especially in LMICs like Peru.

\section{ACKNOWLEDGEMENTS}

None.

\section{FUNDING}

This work was supported by a grant received through the Research Training Fellowship in Public Health and Tropical Medicine of Antonio Bernabe-Ortiz (103994/Z/14/Z), funded by the Wellcome Trust.

\section{COMPETING INTERESTS}

The authors completed the Unified Competing Interest form at http://www.icmje.org/coi disclosure.pdf (available upon request from the corresponding author), and declare no conflicts of interest.

\section{CORRESPONDENCE TO:}

Meera F. Iyengar, BA, MDc

12514 Lynx Lane 
Sugar Land, TX, 77478

USA

meera.iyengar@utsouthwestern.edu

This is an open-access article distributed under the terms of the Creative Commons Attribution 4.0 International License (CCBY-4.0). View this license's legal deed at http://creativecommons.org/licenses/by/4.0 and legal code at http://creativecommons.org/licenses/by/4.0/legalcode for more information. 


\section{REFERENCES}

1. Worldwide trends in diabetes since 1980: a pooled analysis of 751 population-based studies with 4.4 million participants. Lancet. 2016;387:1513-130. do $\mathrm{i}: 10.1016 / \mathrm{S} 0140-6736(16) 00618-827061677$

2. Guariguata L, Whiting D, Weil C, Unwin N. The International Diabetes Federation diabetes atlas methodology for estimating global and national prevalence of diabetes in adults. Diabetes Res Clin Pract. 2011;94(3):322-332. doi:10.1016/j.diabres.201 1.10 .040

3. Perkins BA, Olaleye D, Zinman B, Bril V. Simple screening tests for peripheral neuropathy in the diabetes clinic. Diabetes Care. 2001;24(2):250-256. do i:10.2337/diacare.24.2.250

4. Brown JJ, Pribesh SL, Baskette KG, Vinik AI, Colberg SR. A comparison of screening tools for the early detection of peripheral neuropathy in adults with and without type 2 diabetes. J Diabetes Res. 2017;2017:1467213. doi:10.1155/2017/1467213

5. Jayaprakash P, Bhansali A, Bhansali S, Dutta P, Anantharaman R, Shanmugasundar G. Validation of bedside methods in evaluation of diabetic peripheral neuropathy. Indian J Med Res. 2011;133:645-649.

6. Katulanda P, Ranasinghe P, Jayawardena R, Constantine GR, Sheriff MHR, Matthews DR. The prevalence, patterns and predictors of diabetic peripheral neuropathy in a developing country. Diabetol Metab Syndr. 2012;4:21. doi:10.1186/1758-59 96-4-21

7. Garoushi S, Johnson M, Tashani O. Point prevalence of painful diabetic neuropathy in the Middle East and North Africa region: A systematic review with metaanalysis. Libyan J Med Sci. 2018;2:85-94.

8. Lazo ML, Bernabé-Ortiz A, Pinto ME, et al. Diabetic peripheral neuropathy in ambulatory patients with type 2 diabetes in a general hospital in a middle income country: a cross-sectional study. PLOS ONE. 2014;9(5):e95403. doi:10.1371/journal.pone.0095403

9. Singh N, Armstrong DG, Lipsky BA. Preventing foot ulcers in patients with diabetes. JAMA. 2005;293(2):217-228. doi:10.1001/jama.293.2.217

10. Tentolouris N, Al-Sabbagh S, Walker MG, Boulton AJ, Jude EB. Mortality in diabetic and nondiabetic patients after amputations performed from 1990 to 1995: a 5-year follow-up study. Diabetes Care. 2004;27(7):1598-1604. doi:10.2337/diacare.27.7.1598
11. Cárdenas MK, Mirelman AJ, Galvin CJ, et al. The cost of illness attributable to diabetic foot and costeffectiveness of secondary prevention in Peru. BMC Health Serv Res. 2015;15:483. doi:10.1186/s12913-01 5-1141-4

12. Bernabe-Ortiz A, Perel P, Miranda JJ, Smeeth L. Diagnostic accuracy of the Finnish Diabetes Risk Score (FINDRISC) for undiagnosed T2DM in Peruvian population. Prim Care Diabetes. 2018;12(6):517-525. $\underline{\mathrm{d}}$ oi:10.1016/j.pcd.2018.07.015

13. Pourhamidi K, Dahlin LB, Englund E, Rolandsson $\mathrm{O}$. Evaluation of clinical tools and their diagnostic use in distal symmetric polyneuropathy. Prim Care Diabetes. 2014;8(1):77-84. doi:10.1016/i.pcd.2013.0 $\underline{4.004}$

14. Bloom S, Till S, Sonksen P, Smith S. Use of a biothesiometer to measure individual vibration thresholds and their variation in 519 non-diabetic subjects. BMJ. 1984;288(6433):1793-1795. doi:10.113 6/bmj.288.6433.1793

15. Babor TF, Saunders JB, Monteiro MG. AUDIT: The Alcohol Use Disorders Identification Test - Guidelines for Use in Primary Care 2001. Accessed July 12, 2019. https://apps.who.int/iris/handle/10665/67205

16. Barros AJ, Hirakata VN. Alternatives for logistic regression in cross-sectional studies: an empirical comparison of models that directly estimate the prevalence ratio. BMC Med Res Methodol. 2003;3:21. $\underline{\mathrm{d}}$ oi:10.1186/1471-2288-3-21

17. Ribeiro de Souza L, Debiasi D, Bisognin Ceretta L, Simões PW, Tuon L. Meta-analysis and metaregression of the prevalence of diabetic peripheral neuropathy among patients with type 2 diabetes mellitus. Int Arch Med. 2016;9. doi:10.3823/1936

18. Tres GS, Lisbôa HRK, Syllos R, Canani LH, Gross JL. Prevalence and characteristics of diabetic polyneuropathy in Passo Fundo, South of Brazil. Arq Bras Endocrinol Metabol. 2007;51(6):987-992. doi:10.1 590/s0004-27302007000600014

19. Paisey RB, Arredondo G, Villalobos A, Lozano O, Guevara L, Kelly S. Association of differing dietary, metabolic, and clinical risk factors with microvascular complications of diabetes: a prevalence study of 503 Mexican type II diabetic subjects. II. Diabetes Care. 1984;7(5):428-433. doi:10.2337/diacare.7.5.428 
20. Ashok S, Ramu M, Deepa R, Mohan V. Prevalence of neuropathy in type 2 diabetic patients attending a diabetes centre in South India. J Assoc Physicians India. 2002;50:546-550.

21. Weerasuriya N, Siribaddana S, Dissanayake A, Subasinghe Z, Wariyapola D, Fernando DJ. Long-term complications in newly diagnosed Sri Lankan patients with type 2 diabetes mellitus. OJM.

1998;91(6):439-443. doi:10.1093/qimed/91.6.439

22. International Diabetes Federation. Published 2015. Accessed April 3, 2019. http://www.idf.org

23. Petropoulos IN, Ponirakis G, Khan A, Almuhannadi H, Gad H, Malik RA. Diagnosing Diabetic Neuropathy: Something Old, Something New. Diabetes Metab J. 2018;42(4):255-269. doi:10.40 93/dmj.2018.0056

24. Won JC, Park TS. Recent Advances in Diagnostic Strategies for Diabetic Peripheral Neuropathy. Endocrinol Metab (Seoul). 2016;31(2):230-238. doi:1 0.3803/enm.2016.31.2.230

25. Mythili A, Kumar KD, Subrahmanyam KAV, Venkateswarlu K, Butchi RG. A Comparative study of examination scores and quantitative sensory testing in diagnosis of diabetic polyneuropathy. Int J Diabetes Dev Ctries. 2010;30(1):43-48. doi:10.4103/0973-393 $\underline{0.60007}$
26. Stino AM, Smith AG. Peripheral neuropathy in prediabetes and the metabolic syndrome. J Diabetes Investig. 2017;8(5):646-655. doi:10.1111/jdi.12650

27. Dyck PJ, Clark VM, Overland CJ, et al. Impaired Glycemia and Diabetic Polyneuropathy. Diabetes Care. 2012;35(3):584-591. doi:10.2337/dc11-1421

28. Bansal D, Gudala K, Muthyala H, Esam HP, Nayakallu R, Bhansali A. Prevalence and risk factors of development of peripheral diabetic neuropathy in type 2 diabetes mellitus in a tertiary care setting. $J$ Diabetes Investig. 2014;5(6):714-721. doi:10.1111/idi.1 $\underline{2223}$

29. Ang L, Jaiswal M, Martin C, Pop-Busui R. Glucose control and diabetic neuropathy: lessons from recent large clinical trials. Curr Diab Rep. 2014;14(9):528. do i:10.1007/s11892-014-0528-7

30. Chung JO, Cho DH, Chung DJ, Chung MY. Association between diabetic polyneuropathy and cardiovascular complications in type 2 diabetic patients. Diabetes Metab J. 2011;35(4):390-396. doi:1 0.4093/dmi.2011.35.4.390 